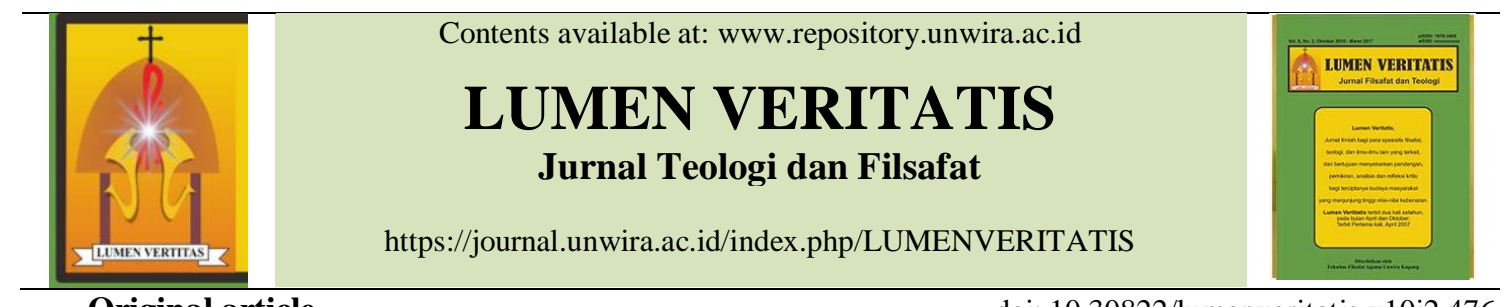

Original article

\title{
KRISIS SEXUAL ABUSE DI USA DAN PEMBELAJARAN BAGI GEREJA INDONESIA
}

\author{
Agustinus Tri Edy Warsono \\ Alumnus Universitas Kepausan Lateran, Roma \\ Pengajar Hukum Gereja di Fakultas Teologi \\ Universitas Sanata Dharma, Yogyakarta \\ Email: ag_tried@yahoo.co.id
}

\begin{abstract}
Sex abuse in the USA leads the church to the bankruptcies and lost her credibility because the priests have mismanaged their authority for their own interests. The faithful are angry to the hierarchy, seeing that most of the victims are children under age, and they do not have any power to escape from the abusive relationship. The church in Indonesia should learn from the cases in the USA, and prepares the Indonesian priests and all people working in the Church to apply the ethical conducts of profession.
\end{abstract}

Keywords: sex abuse, ethical conducts, Indonesian Church, protection for the minor in the church, Gravioribus Delictis

Persoalan sexual abuse di USA bermula dari koran Boston Globe yang mengadakan investigasi tentang kasus pelecehan seksual oleh para imam pada anak-anak yang terjadi di Keuskupan Agung Boston. Tanggal 6 Januari 2002 Boston Globe melaporkan bahwa ada 58 imam di Keuskupan Boston telah melakukan pelecehan seksual sejak tahun 1950 - 2002 dan mereka tidak mendapat hukuman. Para imam pelaku kebanyakan hanya dipindah dari satu paroki ke paroki lain. Uskup Agung Boston, Kardinal Law, sebenarnya telah mengetahui persoalan tersebut, dan ada indikasi bahwa Bapa Uskup berusaha menutupinya. Tanggal 13 Des 2002, sekitar 25.000 kelompok Katolik di Boston menuntut Kardinal Law mundur dari jabatannya. Akhirnya Kardinal Law mengundurkan diri sebagai uskup
Boston dan Paus menerima pengunduran diri tersebut, lalu memindahkan Kardinal Law ke Roma. Sampai pada akhir hidupnya tahun 2017, Kardinal Law tak pernah terjamah hukuman pidana karena kasus pelecehan seksual yang terjadi di Boston.

Dari Boston, kasus pelecehan seksual dalam Gereja menggelinding seperti bola salju liar yang membuka tabir kasus di berbagai belahan dunia mulai dari Amerika Latin, Eropa dan Australia. Puncak dari kasus ini adalah pada bulan September 2018 lalu ketika Mahkamah Tinggi Amerika memerintahkan beberapa keuskupan di USA (Philadelphia, New Jersey, dan Florida) untuk membuka kembali dokumen Gereja dari tahun 1950 - 2018 guna melihat apakah ada kasus-kasus pelecehan yang disembunyikan Gereja. 
Persoalan ini juga mengarahkan konflik internal Gereja antara Paus Fransiscus dan Mgr. Vigano bahwa Vigano meminta Paus mundur dari jabatannya karena tidak berhasil menuntaskan kasus pelecehan seksual selama ini (26 Agustus 2018).

Paper ini berusaha menelusuri persoalan pelecehan seksual di USA dan pengaruhnya bagi kepemimpinan Paus Fransiskus dalam menanggapi kasus sexual abuse yang melanda sebagian besar keuskupan di Amerika dan Eropa. Beberapa pertanyaan yang hendak dijawab dalam paper ini adalah: seberapa banyak kasus pelecehan seksual yang terjadi di USA? Bagaimana kasus tersebut mempengaruhi kehidupan menggereja umat? Bagaimana Vatikan menanggapi kasus ini? Dan apa yang bisa dipelajari oleh Gereja Indonesia dari kasus pelecehan seksual tersebut?

\section{A. Data Kasus Pelecehan Seksual}

Populasi Katolik di USA ada sekitar 57 juta jiwa, dan tak terbilang banyaknya anak-anak dan orang muda yang mendapat Pendidikan di sekolah Katolik USA. Setiap tahunnya ada sekitar 7 juta orang menerima pelayanan sosial dan kesehatan dari sekitar 800 fasilitas rumah sakit dan klinik yang tersebar di seluruh USA. ${ }^{1}$ Oleh karenanya, tak terhitung jumlahnya orang-orang yang setiap hari berinteraksi dengan para imam, biarawan/wati, serta para pegawai yang bekerja dalam institusi Katolik.

1 Thomas G. Plante dan Courtney Daniels. "The seksual abuse crisis in the Roman Catholic Church: what psychologist and counselors should know," Pastoral Psychology Vol. 52 (2004): 381-382.
Interaksi antara umat dan para imam/biarawan/wati ternyata bisa memunculkan relasi yang tidak sehat ketika para pekerja Gereja tersebut memiliki persoalan seksual. Biasanya orang-orang yang menjadi kurban kekerasan seksual adalah mereka yang kenal dekat dan terbiasa berelasi dengan para imam, misalnya: anak-anak sekolah, misdinar, dan muda-mudi yang beraktivitas di lingkungan Gereja. Mereka menaruh kepercayaan yang besar pada para imam/biarawan karena dipandang sebagai seorang yang baik dan suci dalam Gereja. Namun kepercayaan mereka ini disalahgunakan oleh para imam yang menjadi predator bagi anak-anak tersebut.

Paus Yohanes Paulus II menyebutkan bahwa kejahatan seksual oleh klerus adalah dosa berat dan tindakan kriminal. Dalam konteks paper ini, kejahatan seksual oleh klerus (imam/biarawan) memasukkan terminologi "pedofilia" yaitu adanya kontak seksual, interaksi, intercourse dengan anak-anak yang belum mengalami pubertas maupun anak yang berumur antara 14- 18 tahun, baik dengan terpaksa atau tidak terpaksa. Dalam kanon hukum Gereja no. 1395 disebutkan bahwa imam yang melakukan kejahatan seksual akan dilepaskan dari semua jabatan Gerejawi dan diminta untuk menyesali diri. Mereka akan diserahkan pada proses hukum sipil untuk menerima konsekuensi tindakannya. ${ }^{2}$

22 Jo R. Formicola. "The Vatican, the American bishops, and the church-state ramifications of clerical seksual abuse," Jurnal of Church and State, January (2008): 482. 
Penelitian selama 25 tahun dari fasilitas klinik psikologi untuk para imam dan biawan/wati yang berjumlah sekitar 1. 322 orang imam menyatakan bahwa ada sekitar 2,7\% kasus pelecehan seksual pada anak-anak di bawah 18 tahun, dan $61 \%$ imam yang diteliti tidak terlibat dalam kasus seksual. Penelitian lain di USA semenjak tahun 1960-2004 ada sekitar 800 kasus pelecehan seksual pada anak yang dilaporkan, dan ada 300 imam yang telah dilaporkan melakukan pelecehan seksual pada anak-anak. ${ }^{3}$ Plante (1999) menggabungkan penelitian dari klinik rehabilitasi Canada dan data para peneliti di Amerika, dia menyimpulkan bahwa ada sekitar 6\% imam terlibat dalam kasus pelecehan. Artinya ada sekitar 900 imam terlibat dalam kasus pelecehan mulai dari tahun $1950-1999 .{ }^{4}$

Data terakhir tahun 2018 menunjukkan ada sekitar 300 imam di Keuskupan Philadelphia telah melakukan pelecehan seksual pada sekitar 1000 anak-anak dari tahun 1940 - 2018. Pada bulan Agustus 2018, Grand Jury di negara bagian Pennsylvania (PA) mengeluarkan laporan setebal 900 halaman yang menyatakan bahwa pelecehan seksual pada anak-anak sungguh terjadi, dan meminta semua keuskupan di wilayah PA memberikan dokumen Gereja pada hakim negara

3 Departemen kehakiman USA merumuskan tindakan kekerasan seksual adalah "segala bentuk kontak seksual dan tingkah laku seksual yang terjadi tanpa persetujuan yang explisit dari salah satu orang yang terlibat dalam relasi seksual." Bentuk kekerasan tersebut bisa berupa tindakan relasi intercourse, memegang anggota tubuh yang berhubungan dengan genital, dan memperlihatkan anggota tubuh genital pada orang lain.

${ }^{4}$ Ibid., 384. untuk diselidiki. Sekarang ini hampir semua keuskupan di USA memberikan pernyataan untuk bersedia bekerja sama dengan pengadilan guna membuka dokumen untuk melihat kasus-kasus pelecehan yang terjadi selama ini. Tanggal 14 September 2018, Keuskupan Salt Lake City menyatakan bahwa ada 16 imam Katolik yang sedang diproses dalam kasus pelecehan pada 34 anakanak sejak tahun 1990. Tanggal 8 Oktober 2018, Keuskupan Owensboro, Kentucky menyatakan bahwa ada 27 imam yang terkena kasus pelecehan seksual sejak tahun 1937. Ada 15 keuskupan di negara bagian Texas yang akan mempublikasikan nama-nama imam yang terlibat dalam pelecehan seksual paling lambat pada 31 Januari 2019. 5

Kasus pelecehan seksual tidak hanya melibatkan para imam, tapi juga para uskup yang dengan sengaja atau tidak sengaja menutupi kasus-kasus yang terjadi di keuskupannya. Mantan Kardinal McCarrick adalah uskup agung emeritus untuk keuskupan Washington DC dan dia diangkat menjadi Kardinal tahun 2001. Tahun 2017 McCarrick dituduh telah melakukan pelecehan seksual pada seorang anak misdinar di New York saat McCarrick bertugas di sana 40 tahun lalu. ${ }^{6}$ Bulan Agustus

${ }^{5} \mathrm{PBS}$, "How a Catholic sex abuse report in Pennsylvania echoed around the USA," 19 Oct 2018. Accessed on 11 Nov 2018:

https://www.pbs.org/newshour/nation/ho w-a-catholic-sex-abuse-report-inpennsylvania-echoed-around-the-u-s. 6 Jim, bukan nama aslinya menyatakan bahwa tahun 1969 saat dia berumur 11 tahun diajak McCarrick tidur di kamarnya dan dia melakukan kekerasan 
2018, Paus mencopot jabatan Kardinal dari McCarrick, dan kini pada usia 88 tahun dia dijatuhi hukuman tahanan rumah, dan dilarang dekat dengan anakanak. Bulan Juli 2018, Uskup agung Philip Wilson dari keuskupan Adelaide, Australia juga mengundurkan diri karena dia dinyatakan bersalah oleh pengadilan karena telah menyembunyikan kasus pelecehan seksual para imamnya. Dia dihukum 1 tahun penjara dan dicopot dari jabatan uskupnya. Pada tanggal 21 September 2018, Paus menerima pengunduran diri 5 uskup dari Chili yang terkena kasus telah menutupi persoalan pelecehan seksual beberapa imam di keuskupan mereka.

Persoalan pelecehan seksual telah merebak di berbagai keuskupan di dunia. Paus mengundang para Uskup di seluruh dunia untuk mengadakan sinode di Roma guna membahas persoalan ini pada tanggal 20-24 Februari 2019. Kini masalah pelecehan seksual bukan hanya persoalan lokal USA tapi telah menjadi masalah Gereja universal dan negara karena para uskup dan imam yang terlibat sudah dan masih berurusan dengan polisi serta pengadilan. Para kurban menuntut agar mereka yang terlibat dilepaskan dari jabatan gerejawi serta mendapat hukuman yang setimpal dari pengadilan sipil negara.

seksual padanya selama puluhan tahun. Sampai usia 30 tahun, Jim merasa bersalah atas dirinya sendiri dan jatuh pada obat bius serta minuman keras. Beberapa kali dia ingin bunuh diri. Jim menyerahkan kasusnya pada polisi di Virginia untuk ditangani. Lihat Sarah Rankin, "More details emerge on latest sex abuse allegations against Cardinal McCarrick," Crux, 21 Juli 2018.

\section{B. Gereja Setelah Sexual Abuse}

Sebelum Boston Globe memberitakan kasus pelecehan seksual di keuskupan agung Boston, Gereja sering kali menangani kasus imam yang melakukan kejahatan seksual dengan memberi kompensasi pada pihak keluarga atau kurban, dan tidak memberi tindakan administratif serta hukuman pada sang imam. New York Times dan Boston Globe menemukan fakta bahwa Keuskupan Boston menyelesaikan 50 kasus kejahatan seksual Rm. Joseph Geoghan dengan memberi kompensasi \$10 juta pada para kurban. Rm. Geoghan dituduh melakukan kejahatan pedophilia dari tahun 1962-1995. Namun demikian keuskupan Boston tidak menghentikan dan menghukum pastor Geoghan agar tidak melakukan kesalahan yang sama lagi.

Menanggapi persoalan kejahatan seksual di Boston, Paus Yohanes Paulus II mengundang beberapa kardinal USA untuk mengadakan pertemuan. Pertemuan itu menghasilkan 6 prinsip dasar. ${ }^{7}$ Pertama, kejahatan seksual, terutama kejahatan seksual pada anakanak oleh klerus adalah tindak kriminal dan dosa berat. Kedua, Gereja bersolider dengan kurban dan bersedia memberi bantuan pada keluarga kurban. Ketiga, seluruh pemimpin Gereja perlu sadar akan pentingnya kasus kejahatan seksual ini, terlepas berapa jumlah kasus di masing-masing keuskupan. Keempat, tidak ada kaitan langsung antara pedophilia dan selibat para imam bahwa selibat menjadi alasan para imam melakukan pedophilia. Kelima, pemimpin Gereja perlu mengadakan koreksi ajaran moral tentang sexual

${ }^{7}$ Formicola, "The Vatican, the American bishops, and the Church-state," 488. 
abuse, mengunjungi rumah pembinaan imam untuk menyeleksi lebih teliti para kandidat yang akan menjadi imam. Keenam, Gereja meyakini kekuatan dari pertobatan Kristiani yaitu tindakan radikal untuk berbalik dari dosa dan kembali pada Allah.

Pertemuan Uskup Amerika di Dallas tahun 2002 merumuskan normanorma dasar bagi kasus pelecehan seksual. Norma dasar ini lebih progresif dibanding enam prinsip yang dibicarakan oleh Paus dan para Kardinal. Pokok-pokok norma dasar tersebut adalah: (1) Gereja memberikan sarana penyembuhan dan rekonsiliasi dengan kurban pedophilia. (2) Gereja akan segera bertindak bila ada tuduhan dan laporan kejahatan seksual: menyerahkan kasus pada hukum sipil, melepaskan para imam tertuduh dari tugas untuk dievaluasi secara medis dan psikologis. (3) Para uskup menjamin akuntabilitas tindakan mereka atas kasus pelecehan seksual, serta mendirikan kantor National Gerejawi untuk perlindungan pada anak-anak dan remaja. (4) Uskup menjamin perlindungan pada anak dan remaja serta melakukan tindakan preventif. Hal yang dilakukan adalah membuat program pelatihan pastoral yang beretika, serta penyelidikan calon imam dengan lebih teliti.

Berdasar norma dasar di atas, Gereja mengambil berbagai kebijakan sebagai usaha preventif agar peristiwa itu tidak terulang lagi. Kebijakan pertama adalah "zero tolerant policy" yaitu tidak ada toleransi bagi siapa pun yang bekerja di dalam Gereja bila terkena kasus seksual. Seseorang akan langsung dilepaskan dari pekerjaan dan dibebas-tugaskan dari segala tanggung jawab bila dia dituduh telah melakukan kejahatan seksual. Selanjutnya Gereja akan menyerahkan sang tertuduh untuk menghadapi proses hukuman sipil. Gereja akan bekerja sama dengan pihak pengadilan sampai kasusnya selesai. Apabila dinyatakan bersalah, sang tertuduh akan menjalani hukuman sesuai dengan tuntutan pengadilan sipil.

Kebijakan kedua adalah Gereja USA mengadakan pelatihan "Safe environment training" untuk semua orang yang bekerja dalam institusi Katolik: rumah sakit, Gereja, sekolah, kelompok sosial dan organisasi organisasi resmi atas nama Gereja Katolik. Setiap tahun semua pegawai harus mengikuti pelatihan ini yang mengajari soal etika profesi dan batasanbatasan dalam pelayanan pastoral Gereja. Pelatihan ini dilakukan secara online atau pertemuan pelatihan dalam tiap keuskupan selama 3 jam. ${ }^{8}$ Sesudah pelatihan, setiap peserta akan mendapat sertifikat tanda keikutsertaan yang membuat dia memiliki ijin untuk bisa bekerja atau menjadi volunteer di dalam organisasi Gereja. Tanpa sertifikat tersebut, seorang imam/suster/bruder dan pegawai awam tidak akan mendapat ijin

8 Keuskupan Oakland, California mewajibkan semua pekerja (Imam, bruder, suster, pegawai) dan tenaga sukarela yang bekerja dalam institusi Gereka Keuskupan Oakland untuk mengikuti pelatihan "Safe environment training". Dalam website Keuskupan Oakland dijelaskan bagaimana proses pendaftaran, pelatihan, serta penyerahan sertifikat kalau seorang pekerja sudah mengikuti pelatihan ini. Setiap orang diwajibkan membaharui training selama setahun sekali. Lihat: https://www.oakdiocese.org/offices/safeenvironment. 
untuk terlibat dalam karya pastoral gerejawi.

Prinsip dasar penanganan pelecehan seksual membuat pemimpin Gereja tidak bisa lagi menyembunyikan imam yang melakukan tindak kejahatan. Bahkan Mahkamah Pengadilan Tinggi negara bagian di USA bisa meminta Gereja untuk membuka bagi publik dokumen tentang para imam yang terlibat kasus pedophilia. Hal itu bisa menjadi bukti bagaimana para pemimpin menangani kasus kejahatan seksual dalam Gereja. Laporan keuangan dan dokumen administrasi yang ada di semua institusi Gereja juga bisa dibuka oleh publik bila diperlukan dalam kasus pelecehan seksual oleh imam. Kebijakan tersebut membawa perubahan yang besar dalam Gereja Katolik. Sebelumnya semua laporan dan dokumen Gereja bersifat rahasia dan hanya dapat diakses oleh orang-orang yang berwenang dalam Gereja. Kini Gereja Amerika terbuka pada otoritas sipil untuk mengadakan investigasi dalam Gereja sejauh berhubungan dengan kasus pelecehan seksual oleh imam atau pekerja dalam institusi Gereja Katolik USA.

\section{Sikap Paus Fransiskus Pada Persoalan Pelecehan Seksual}

Bulan Oktober 2018, Mahkamah Agung USA memerintahkan 13 negara bagian untuk membuka dokumendokumen Gereja Katolik sejak tahun 1940 - 2018 guna memeriksa kasus pelecehan seksual dalam Gereja. Saat ini Gereja Amerika ada pada titik kepercayaan terendah karena persoalan pelecehan seksual yang tak kunjung henti sejak awal tahun 2002. Banyak orang mengkritik Paus Fransiscus karena dia dianggap tidak cukup bertindak cepat untuk menanggapi persoalan tersebut.
Para penyerang Paus Fransiskus, salah satunya mantan diplomat Vatikan untuk USA mengirim surat kepada Vatikan 11 halaman: menuntut Paus untuk mundur karena sebenarnya Paus Fransiskus tahu tentang persoalan Kardinal McCarrick di tahun 2013, tapi Vatikan tidak segera mengambil tindakan.

Tanggal 7 Oktober 2018, Kongregasi Uskup mengeluarkan surat tanggapan atas tuduhan Mgr. Vigano. Setelah menyelidiki dokumen Gereja tentang bagaimana Mgr. McCarrick bisa meniti kariernya hingga menjadi Kardinal, Vatikan menyatakan bahwa Paus Fransiskus dan pendahulunya, Paus Benediktus XVI tidak mengetahui sama sekali persoalan pelecehan seksual yang telah dilakukan oleh mantan Kardinal McCarrick. Surat tanggapan itu juga menyatakan: "Baik kejahatan dan tindakan menutupi kejahatan (seksual) tidak dapat lagi ditoleransi; dan privilese dan tindakan yang berbeda untuk uskupuskup yang telah melakukan kejahatan seksual atau menutupinya, pada dasarnya menyatakan sebuah tindakan klerikalisme yang tidak dapat diterima". ${ }^{9}$

Sudah beberapa kali Paus Fransiskus bertemu dengan kurban pelecehan seksual di beberapa negara. Tahun 2014, Paus bertemu dengan 6 orang kurban pelecehan di Vatikan dan mengadakan misa bersama mereka. Tahun 2016, Paus bertemu dengan 5 kurban (3 laki-laki dan 2 perempuan) di seminari St. Karolus Boromeus,

9 Gerald O'Connell. "Cardinal Marc Ouellet responds to Viganò charges, accuses him of blasphemy," America Magazine, Oct 7, 2018. Link:

https://www.americamagazine.org/faith/2018/10/ 07/cardinal-marc-ouellet-responds-viganocharges-accuses-him-blasphemy. 
Philadelphia, USA. Paus meminta ampun dan maaf dari mereka sembari berkata, "Saya meminta maaf karena kedosaan itu juga bagian dari para pemimpin Gereja yang tidak menanggapi dengan cukup persoalan pelecehan seksual yang dilaporkan oleh anggota keluarga atau oleh kurban sendiri". Bulan Mei dan Agustus 2018, Paus juga bertemu dengan beberapa kurban pelecehan seksual oleh imam dari Chile dan Irlandia.

Pertemuan kurban pelecehan dengan Paus memberi kesempatan bagi Paus Fransiskus untuk mendengar sendiri bagaimana penderitaan emosional dan sosial yang dialami oleh para kurban. Pengalaman pelecehan membuat para kurban menjadi orang yang merasa diri tidak berharga dan kehidupan mereka dihancurkan oleh para pelaku kejahatan. Pertemuan tersebut memberi perspektif persoalan kejahatan seksual dari sisi para kurban. ${ }^{10}$ Seorang kurban berinisial "Jim" menyatakan bahwa pelecehan yang terjadi beberapa tahun membuat dia merasa bersalah dan malu. Meski peristiwa tersebut telah terjadi beberapa puluh tahun lalu, tetap saja meninggalkan luka dan persoalan kepribadian yang berkepanjangan. Jim berjuang untuk lepas dari alkohol yang membuat dia gagal dalam perkawinan dan berusaha bunuh diri beberapa kali. ${ }^{11}$

10 NPR. "Pepe cannot claim he was misinformed: Chilean abuse survivor after Vatican meeting." 10 Mei 2018. Link:https://www.npr.org/sections/parall els/2018/05/10/609182908/pope-cannotclaim-he-was-isinformed-chilean-abusesurvivor-after-vatican-meeting.

11 Rankin, "More details emerge on latest sex abuse allegations against
Akhir Agustus 2018, Paus mengeluarkan surat "To the people of God" sebagai refleksi dan tanggapan Gereja atas kasus yang melanda USA. Di awal surat, Paus meminta pengampunan atas derita yang dialami oleh kurban kekerasan seksual, "Dengan rasa malu dan pertobatan, kita menyadari sebagai komunitas Kristiani bahwa kita berada pada jalan yang tidak semestinya, bahwa kita tidak bertindak dengan benar, untuk menyadari betapa besar dan beratnya kerusakan yang telah dilakukan pada banyak orang. Kita tak peduli pada mereka yang kecil; kita menyingkirkan mereka. Derita para kurban dan keluarganya adalah derita kita juga. Oleh karenanya, hal ini menjadi mendesak bahwa kita sekali lagi menekankan komitmen untuk melindungi anak-anak dan orang-orang dewasa yang mudah terluka". ${ }^{12}$ Sayangnya dalam surat ini Paus tidak memberi indikasi dalam konkret apa Vatikan akan memberi sanksi pada uskup-uskup jika mereka menutup-nutupi kasus pelecehan yang dilakukan oleh para imam.

13 November 2018, Paus Fransiskus memilih uskup agung Charles Scicluna dari Malta, Italia menjadi pemimpin untuk komisi melawan kasus sexual abuse dalam Gereja dan perlindungan bagi anak dan remaja. Mgr. Scicluna telah dikenal selama bertahun-tahun sebagai figur

Cardinal McCarrick," Crux, 21 Juli 2018.

12 Pope Francis. "Letter of His Holiness Pope Francis to the people of God," Agustus 2018. Link: http://w2.vatican.va/content/francesco/en letters/2018/documents/papa-

francesco_20180820_lettera-popolodidio.html. 
yang gigih memperjuangkan perlindungan anak-anak dan remaja dari kejahatan seksual. Dia pula akan terlibat menyiapkan pertemuan 130 uskup dari perwakilan tiap benua guna membicarakan persoalan sexual abuse pada bulan Februari 2019 mendatang di Vatikan.

\section{Perspektif Yuridis Atas Pelecehan Seksual Para Imam Terhadap Anak-Anak}

\section{D.1. Kitab Hukum Kanonik 1983}

Kitab Hukum Kanonik (KHK) 1983 dalam kanon $1395 \quad \S 2$ menandaskan pandangan Gereja secara yuridis berkaitan dengan pelecehan seksual oleh para imam kepada anakanak: "Klerikus yang melakukan kejahatan lain melawan perintah keenam dari Dekalog, apabila tindakpidana itu dilakukan dengan paksaan atau ancaman atau secara publik atau dengan anak di bawah umur enambelas tahun, hendaknya dihukum dengan hukuman-hukuman lain yang adil, tak terkecuali, jika perlu, dikeluarkan dari status klerikal". Dari kanon ini, Gereja memandang bahwa perbuatan pelanggaran seksual yang dilakukan oleh klerus menunjuk pada tiga unsur yang memberatkan: a) menggunakan paksaan atau ancaman; b) dilakukan secara publik dalam arti bahwa tindakan itu berlangsung di tempat umum atau terbuka terhadap publik, atau hanya jika dilihat oleh beberapa orang saja; c) dilakukan dengan anak di bawah umur enambelas tahun. Maka, pelanggaran seksual oleh klerus terhadap anak-anak di bawah umur adalah sebuah kejahatan yang perlu mendapat sanksi atau hukuman yang dijatuhkan oleh otoritas Gereja yang berwenang.
Hukuman atau sanksi yang diterapkan pada seorang klerus biasanya ada dalam dua bentuk: 1) Tindakan yang melarang seluruh pelayanan publik atau setidaknya mencegah klerus tersebut untuk mengadakan kontak dengan anakanak $^{13}$ dan tindakan ini dapat diperkuat dengan pernyataan hukum; 2) Hukumanhukuman gerejawi, yang salah satunya paling berat adalah dikeluarkan dari status klerus. Sifat dari hukuman ini pada dasarnya adalah tidak terbatas, "iustis poenis puniantur", akan tetapi jika dirasa dibutuhkan (si casus ferat) dapat diaplikasikan hukuman yang terberat yakni dikeluarkan dari status klerus. $^{14}$

\section{D.2. Motu proprio Sacramentorum Sanctitatis Tutela}

13 Misalnya hukuman yang dijatuhkan kepada Kardinal George Pell di Australia atas pelanggaran seksual yang dilakukannya terhadap beberapa anak di bawah umur:

https://www.repubblica.it/vaticano/2019/ 02/27/news/pedofilia pell in carcere re vocata_liberta_cauzione220237677/?refresh_ce, diakses pada 10 April 2019.

14 Sebagai catatan, kan. $695 \quad \S 1$ memberikan norma yang agak berbeda terkait dengan hukuman atas kejahatan yang dilakukan oleh anggota Tarekat Hidup Bhakti dalam kaitannya dengan pelanggaran dalam kan. 1395 §2: "...kecuali dalam hal kejahatan yang disebut dalam kan. 1395 \$2, Superior menilai bahwa tidak mutlak perlu mengeluarkannya, dan perbaikan anggota, restitusi keadilan dan perbaikan atas skandal cukup dapat diusahakan dengan cara lain". 
Perhatian Gereja terhadap kasuskasus pelanggaran seksual para klerus kepada anak-anak semakin mendapatkan tempatnya pada masa pontifikal Paus Yohanes Paulus II. Paus Yohanes Paulus II, pada tanggal 30 April 2001, mengundangkan motu proprio Sacramentorum Sanctitatis Tutela (SST), ${ }^{15}$ di mana pelanggaran seksual terhadap anak-anak di bawah usia 18 tahun yang dilakukan oleh para klerus dimasukkan ke dalam daftar kejahatankejahatan berat (delicta graviora) yang penyelesaiannya menjadi otoritas Kongregasi untuk Ajaran Iman (Congregation for the Doctrine of Faith $=\mathrm{CDF})$. Ketentuan untuk kejahatan ini ditetapkan 10 tahun mulai dari ketika korban berusia 18 tahun. Motu proprio ini ditujukan kepada para klerus dari Gereja Latin maupun Gereja Timur baik untuk imam diosesan maupun imam religius.

\section{D.2.1. Normae de Gravioribus Delictis}

Pandangan Gereja mengalami perubahan ketika Kardinal Ratzinger, pada tahun 2003, yang kala itu menjadi Prefek untuk Kongregasi Ajaran Iman, mendapatkan konsesi beberapa fakultas khusus dari Paus Yohanes Paulus II yang memungkinkannya melaksanakan proses-proses hukum untuk pelanggaranpelanggaran yang lebih berat. Beberapa fakultas ini meliputi penggunaan proses hukum administratif; sedangkan untuk kasus-kasus yang lebih berat berupa permohonan diberhentikan (dimissio) dari status klerikal secara ex-officio. Fakultas tersebut kini telah diinkorporasikan dalam revisi motu

${ }^{15}$ http://www.vatican.va/resources/resour ces_introd-storica_en.html, diakses pada 08 April 2019. proprio yang disetujui oleh Bapa Suci, Benediktus XVI, pada tanggal 21 Mei 2010. Dalam ketentuan yang baru ini, ketentuan-ketentuan dalam kasus yang menyangkut pelanggaran para klerus terhadap anak-anak di bawah umur ditetapkan 20 tahun dihitung mulai dari ketika korban berusia 18 tahun. Dalam kasus-kasus tertentu, Kongregasi untuk Ajaran Iman dapat menentukannya secara lain. Delik kanon mengenai pencarian, pemilikan dan penyebaran pornografi anak-anak di bawah 14 tahun, a clerico turpe patrata (tindakan memalukan yang dilakukan oleh klerus), dengan cara apa pun juga dibahas secara khusus di dalam motu proprio yang diperbarui ini dalam art. $6 \S 1$ n. $2 .^{16}$

\section{D.2.2. Motu proprio Vos estis lux mundi}

Paus Fransiskus di awal masa kepausan beliau langsung berhadapan dengan banyaknya kasus-kasus pelecehan seksual yang dilakukan oleh para klerus dan terpanggil untuk memberikan perhatian lebih atasnya. Melalui pertemuan dengan beberapa korban pelecehan seksual dari para klerus di beberapa negara dalam kerangka kunjungan pastoralnya, perhatian Paus secara yuridis gerejawi semakin ditampakkan lewat lahirnya motu proprio Vos estis lux mundi (Kamu adalah terang dunia) pada tanggal $9 \mathrm{Mei}$ 2019. ${ }^{17}$ Motu proprio yang dapat

\footnotetext{
${ }^{16}$ http://www.vatican.va/resources/resour ces_rel-modifiche_it.html, diakses pada 28 Agustus 2019.

${ }^{17} \mathrm{http}$ ://w2.vatican.va/content/francesco/ en/motu_proprio/documents/papafrancesco-motu-proprio-20190507_vosestis-lux-mundi.html, diakses pada 29 Agustus 2019.
} 
dikatakan sebagai sebuah langkah maju Gereja dalam menghadapi kejahatan pelanggaran seksualini merupakan hasil pertemuan Komisi Perlindungan Anak di bawah umur yang diadakan di Vatikan pada bulan Februari 2019 di mana seluruh Ketua Konferensi Para Uskup di masing-masing negara hadir terlibat. Motu proprio ini menetapkan normanorma universal yang berlaku untuk seluruh Gereja Katolik di dunia. Adapun beberapa hal baru yang dapat dirangkum dari keseluruhan isi motu proprio ini:

a) Kewajiban bagi setiap keuskupan di dunia untuk mendirikan satu atau lebih sistem publik yang stabil dan mudah diakses untuk penyerahan laporan tentang penyalahgunaan seksual yang dilakukan oleh para imam atau religius, penggunaan pornografi anak dan menyembunyikan penyalahgunaan yang sama (bdk. art. $2 \S 1)$.

b) Kewajiban bagi semua imam dan religius laki-laki maupun perempuan untuk segera melaporkan semua tuduhan penyalahgunaan yang mereka sadari serta segala kelalaian dan penyembunyian dalam mengurus kasus-kasus penyalahgunaan kepada otoritas gerejawi (bdk. art. $3 \S 1)$.

c) Mengatur pula penyalahgunaan seksual dan kekerasan yang diakibatkan oleh penyalahgunaan wewenang, termasuk di dalamnya kasus-kasus kekerasan terhadap para religius oleh para imam, penyalahgunaan yang dilakukan terhadap seminaris dewasa atau para novis (bdk. art. $1 \S 1 . a . i)$.

d) Para Uskup dan Pemimpin Tarekat bertanggungjawab atas tindakan mereka jika berani menyembunyikan kasus penyalahgunaan seksual yang dilakukan oleh para imamnya. Ia yang seharusnya melindungi para korban, malah justru melindungi para tersangka pelaku (bdk. art. 1 $\S 1 . b)$.

e) Penekanan pentingnya melindungi anak-anak di bawah umur dan orang-orang yang rentan (bdk. art. $1 \S 2 . b)^{18}$.

f) Kewajiban untuk melaporkan ke Uskup atau Pemimpin Tarekat setempat tidak mengganggu atau mengubah kewajiban pelaporan lainnya yang mungkin ada dalam undang-undang negara masingmasing (bdk. art. 19).

g) Seseorang yang melaporkan penyalahgunaan tidak dapat

18 Definisi "orang-orang yang rentan" mencakup setiap orang dalam keadaan lemah, kekurangan fisik atau mental, atau perampasan kebebasan pribadi yang pada kenyataannya bahkan kadangkadang membatasi kemampuan mereka untuk memahami atau ingin menolak pelanggaran. 
dikenai prasangka, pembalasan atau diskriminasi karena apa yang mereka laporkan. Para korban dan keluarga mereka harus diperlakukan dengan penuh martabat dan hormat dan harus menerima bantuan rohani, medis dan psikologi yang sesuai (bdk. art. $5 \S 1)$.

h) Mengatur penyelidikan para Uskup, Kardinal, Pemimpin Religius dan semua yang memimpin keuskupan atau Gereja partikular lainnya dalam berbagai kapasitas, baik mereka yang melakukan penyalahgunaan seksual sendiri, yang dituduh telah menyembunyikan, atau gagal mengejar pelanggaran yang mereka ketahui dan yang menjadi tugas mereka untuk menanganinya (bdk. art. 6).

i) Mengatur peran Uskup Agung Metropolitan dalam proses penyelidikan awal jika yang dituduh adalah seorang Uskup dengan mengirimkan laporan status tentang keadaan penyelidikan kepada Takhta Suci (bdk. art. 8).

j) Bantuan kaum awam amat diperlukan dalam proses penyelidikan, akan tetapi perlu dipilih kaum awam yang memenuhi syarat sesuai dengan kebutuhan kasus individual dan bersedia untuk bekerjasama dengan otoritas Gereja (bdk. art. 13).

k) Prinsip asas praduga tak bersalah dari orang yang diselidiki tetap ditegaskan dan dijunjung tinggi (bdk. art. 12 §7).

1) Tidak mengubah hukuman untuk kejahatan yang dilakukan, tetapi menetapkan prosedur untuk melaporkan dan melakukan penyelidikan awal. Pada akhir penyelidikan, Uskup Metropolitan menyampaikan hasilnya ke Dikasteri Vatikan yang berwenang, yakni Kongregasi untuk Ajaran Iman (bdk. art. 7).

Tanggapan atas hadirnya motu proprio Vos estis lux mundi ini amat beragam. Kardinal Marc Ouellet, Prefek Kongregasi untuk para Uskup, menjelaskan bahwa melalui dokumen ini diletakkanlah kesejajaran posisi para imam dan Uskup dalam penanganan kasus pelanggaran seksual yang dilakukan: "kami tidak meminta apa pun lebih dari apa yang telah diminta para imam kami selama bertahun-tahun. Fakta ini menyentuh subjek yang menjadi prioritas utama bagi Paus: tidak hanya harus ada klerikalisme, tetapi juga tidak ada 'elitisme' di antara kita".

Sedangkan menurut Prof. Patrick Valdrini, seorang dosen emeritus Hukum Gereja di Universitas Kepausan Lateran Roma, dengan motu proprio ini, tanggung jawab anggota Gereja yang ditahbiskan mengenai pelecehan seksual tidak lagi hanya dengan pendekatan 
moral tetapi terutama legal. Beliau merasa dokumen ini adalah "teks yang indah yang meminta semua orang yang membacanya untuk dengan cermat menyadari tanggung jawab mereka, termasuk dari sudut pandang hukum. Saya yakin ini bisa dikutip sebagai model definisi untuk kewajiban dan hak umat beriman". 19

\section{D.3. Proses Pidana}

Ketika seorang klerus mendapatkan tuduhan telah melakukan kejahatan pelanggaran seksual terhadap anak-anak di bawah umur, seorang Uskup diosesan atau pemimpin tertinggi dari suatu tarekat religius haruslah bertindak atas dasar tata aturan proses pidana yang telah ditegaskan dalam Kitab Hukum Kanonik 1983. Uskup diosesan atau pemimpin tarekat religius tidak dapat bertindak sewenang-wenang tanpa mengikuti proses peradilan dalam menjatuhkan sebuah keputusan bagi klerus yang dituduh. ${ }^{20}$ Ada beberapa prinsip dan langkah hukum yang harus dilakukan dan ditaati oleh Uskup diosesan maupun pemimpin tarekat religius:

${ }^{19}$ http://jesuits.ca/newsdetail?TN=NEWS-20190523045940, diakses pada 28 Agustus 2019.

20 Kan. 1341 memberikan penjelasan bahwa Ordinaris hanya dapat bertindak dalam mengupayakan prosedur peradilan atau administratif untuk menjatuhkan atau menyatakan hukuman ketika ia menilai bahwa baik peringatan persaudaraan maupun teguran atau sarana-sarana keprihatinan pastoral yang lainnya tidak lagi mencukupi untuk memperbaiki skandal, memulihkan keadilan dan memperbaiki pelaku pelanggaran, yakni para klerus.
1) Tanggung jawab untuk menangani kasus pelanggaran seksual terhadap anak-anak pertama-tama menjadi tanggung jawab para Uskup dan para Provinsial atau pemimpin tarekat religius. Uskup atau Provinsial atau seorang utusan (delegatus) harus melakukan penyelidikan awal (bdk. kan. 1717 $7^{21}$ ). Penyelidikan awal harus dilakukan dengan menghargai privasi pribadi-pribadi yang terlibat sambil memperhatikan reputasi mereka.

2) Sebelum kasus disampaikan kepada CDF, kecuali jika ada indikasi-indikasi berlawanan yang sungguh serius, klerus yang dituduh harus diberi informasi mengenai tuduhan yang telah dibuat dan kepadanya diberikan kesempatan untuk menanggapi tuduhan tersebut (hak untuk menjawab atau membela diri).

${ }^{21}$ Kan. $1717 \S 1$ - Setiap kali Ordinaris mendapat informasi yang sekurangkurangnya mendekati kebenaran mengenai suatu tindak-pidana, hendaknya ia dengan hati-hati melakukan penyelidikan, sendiri atau lewat orang yang cakap, mengenai fakta, keadaan dan imputabilitas (dapat dan harus dipertanggungjawabkan), kecuali penyelidikan itu sama sekali dianggap berlebihan.

$\S 2$ - Haruslah dijaga agar penyelidikan itu jangan sampai membahayakan nama baik seseorang. 
Dalam hal ini, kebijaksanaan Uskup atau pemimpin tarekat religius akan menentukan dalam pemberian informasi kepada klerus yang dituduh.

3) Jika setelah didapat hasil penyelidikan bahwa tuduhan tersebut benar atau tidak keliru, kasus harus disampaikan kepada CDF.

4) $\mathrm{CDF}$ akan mengambil langkah selanjutnya dengan memberikan arahan untuk memastikan bahwa tindakan yang diambil akan menjamin proses yang adil bagi klerus yang dituduh, untuk menghargai hak fundamentalnya untuk membela diri dan memastikan perhatian bagi kebaikan Gereja, khususnya kebaikan bagi para korban.

5) Hanya CDF yang berwenang menerbitkan hukuman yang definitif terhadap pelanggaran klerus dan ketidaklayakannya untuk melaksanakan pelayanan. ${ }^{22}$

22 Kan. 1722 - Untuk menghindari skandal, untuk melindungi kebebasan para saksi dan mengamankan jalannya keadilan, Ordinaris, sesudah mendengarkan promotor iustitiae dan memanggil terdakwa sendiri, pada tahap proses mana pun, dapat memberhentikan terdakwa dari pelayanan suci atau dari suatu tugas serta jabatan gerejawi, mengharuskan atau melarang dia tinggal di suatu tempat atau wilayah, atau juga

\section{E. Pembelajaran Bagi Gereja Indonesia}

Persoalan kejahatan seksual pada anak-anak dan orang dewasa yang dilakukan oleh para imam tentu juga ada dalam Gereja Indonesia. Hanya saja sampai saat ini kita tidak memiliki data yang lengkap berapa jumlah kasus yang telah terjadi, bagaimana tindakan pembesar Gereja terhadap para imam yang melakukan kejahatan tersebut, dan bagaimana Gereja bertanggung jawab pada kurban dan tuntutan keadilan dari keluarga kurban. Harus diakui bahwa kesadaran akan pentingnya tindakan preventif dan penanganan yang serius oleh Gereja Indonesia secara bersama belum terlihat serius dilakukan. Para pemimpin Gereja belum memiliki satu suara bagaimana menangani persoalan kejahatan seksual pada anak-anak dan orang dewasa. Selama ini penanganan kasus diserahkan pada kebijakan masing-masing uskup setempat.

Syukurlah bahwa tahun 2018 ini Badan Kerjasama Bina Lanjut Imam Indonesia telah mengeluarkan sebuah buku panduan "Pelayanan Profesional Gereja Katolik dan Penyalahgunaan Wewenang Jabatan". ${ }^{23}$ Buku ini berisi tentang pedoman dasar perlindungan hak anak dan orang dewasa rentan, protokol,

melarang dia mengambil bagian dalam perayaan Ekaristi secara publik; semua itu, jika alasannya sudah terhenti, harus ditarik kembali, dan dari hukum sendiri berakhir jika proses pidana sudah selesai.

23 Badan Kerjasama Bina Lanjut Imam Indonesia. Pelayanan Profesional Gereja Katolik dan Penyalahgunaan Wewenang Jabatan, (Yogyakarta: Kanisius), 2018. 
serta bentuk formasi dan pelatihan bagi pelayan pastoral dalam Gereja Katolik. Isi buku ini perlu disosialisasi pada semua Imam dan Uskup di Indonesia. Lebih lanjut, Gereja perlu memikirkan sebuah mekanisme bagaimana para pelayan pastoral bisa dilatih dan mendapat pemahaman tentang batasanbatasan yang perlu dilakukan saat berhadapan dengan umat yang dilayani dalam pastoral.

Beberapa hal yang perlu dipersiapkan dan dipikirkan untuk mencegah dan menangani persoalan sexual abuse di Indonesia adalah: pertama, pusat rehabilitasi bagi para imam/biarawan. Dalam kerjasama dengan institusi kesehatan mental, Gereja perlu menyiapkan tempat rehab bagi para imam/biarawan/wati yang menjadi pelaku kasus kejahatan dan pelecehan seksual. Kolaborasi antara psikolog, spiritualis, dan tenaga ahli lain sungguh diperlukan untuk membantu para klerus yang memiliki persoalan kepribadian dan psikologis. Kedua, penanganan bagi kurban dan keluarganya. Para kurban tidak cukup diberi kompensasi dalam bentuk bantuan finansial. Mereka membutuhkan pemulihan psikologis karena mengalami trauma dan kekerasan seksual yang merusak hidup pribadi mereka. Konseling psikologi dan bantuan rehabilitasi untuk mereka diperlukan bagi proses pemulihan dan penyembuhan diri dari pengalaman luka yang merusak. Ketiga, berbagi data. Masing-masing keuskupan perlu untuk berbagi data tentang persoalan kejahatan seksual yang dilakukan oleh para imamnya. Tentu saja tidak semua orang bisa membuka data tersebut! Data ini akan berguna bagi penelitian dan pengembangan bagaimana Gereja bisa membantu para imam yang bermasalah dan melakukan tindakan preventif agar tidak terulang persoalannya. Keempat, adanya prosedur dan norma-norma dasar yang sama dalam menangani kasus sexual abuse. Gereja Indonesia perlu membuat pedoman pokok bagaimana persoalan kejahatan seksual klerus ditangani dengan prosedur yang sama. Pedoman dan norma yang jelas bisa membantu para uskup dalam mengambil tindakan pada orang-orang yang melakukan abuse dalam lingkungan Gereja.

Akhirnya, persoalan sexual abuse yang semula hanya terjadi di USA telah menyebar ke seluruh dunia. Beberapa negara di Asia Tenggara seperti Singapura dan Philippines sudah bersikap protektif terhadap anak-anak dengan membuat aturan-aturan yang jelas bagaimana para pekerja Gereja harus bersikap terhadap anak-anak. Kalau Gereja Indonesia tidak segera mulai membuat aturan yang jelas dan berstandar nasional soal sexual abuse ini, Gereja akan kehilangan momentum akan pentingnya usaha melindungi anakanak. Bagaimanapun, persoalan sexual abuse pada anak-anak ini harus mendapat perhatian bersama baik dari hierarki maupun dari umat beriman. Jangan sampai Gereja Indonesia porakporanda karena persoalan yang telah dialami oleh Gereja Amerika.

\section{Daftar Pustaka}

Badan Kerjasama Bina Lanjut Imam Indonesia. Pelayanan Profesional Gereja Katolik dan Penyalahgunaan Wewenang Jabatan, (Yogyakarta: Kanisius), 2018.

Formicola, Jo R. "The Vatican, the American bishops, and the church- 
state ramifications of clerical seksual abuse," Jurnal of Church and State, January (2008).

NPR. "Pepe cannot claim he was misinformed: Chilean abuse survivor after Vatican meeting." 10 Mei 2018. Link:

https://www.npr.org/sections/parallels/2 018/05/10/609182908/pope-cannotclaim-he-was-misinformed-chileanabuse-survivor-after-vatican-meeting.

O'Connell, Gerald. "Cardinal Marc Ouellet responds to Viganò charges, accuses him of blasphemy," America Magazine, Oct 7, 2018. Link: https://www.americamagazine.org/faith/ 2018/10/07/cardinal-marc-ouelletresponds-vigano-charges-accuses-himblasphemy.

Plante, Thomas G. dan Courtney Daniels. "The seksual abuse crisis in the Roman Catholic Church: what psychologist and counselors should know," Pastoral Psychology Vol. 52 (2004): 381-382.

PBS, "How a Catholic sex abuse report in Pennsylvania echoed around the USA," 19 Oct 2018. Accessed on 11 Nov 2018.2 Link: https://www.pbs.org/newshour/nation/ho w-a-catholic-sex-abuse-report-inpennsylvania-echoed-around-the-u-s.

Pope Francis. "Letter of His Holiness Pope Francis to the people of God," Agustus 2018. Link: http://w2.vatican.va/content/francesco/en letters/2018/documents/papafrancesco_20180820_lettera-popolodidio.html.

Pope Francis, "Motu proprio Vos estis lux mundi," link:http://w2.vatican.va/content/frances co/en/motu_proprio/documents/papafrancesco-motu-proprio-0190507_vosestis-lux-mundi.html.
Rankin, Sarah, "More details emerge on latest sex abuse allegations against Cardinal McCarrick," Crux, 21 Juli 2018.

Penulis

Dr. Agustinus Tri Edy Warsono, Pr

Alumnus Universitas Kepausan Lateran, Roma

Pengajar Hukum Gereja di Fakultas Teologi

Universitas Sanata Dharma, Yogyakarta 